\title{
Modified BODE indexes: Agreement between multidimensional prognostic systems based on oxygen uptake
}

This article was published in the following Dove Press journal:

International Journal of COPD

3 May 2010

Number of times this article has been viewed

\section{José Luis Lopez-Campos \\ Pilar Cejudo \\ Eduardo Marquez \\ Francisco Ortega \\ Esther Quintana \\ Carmen Carmona \\ Emilia Barrot}

Unidad Médico-Quirúrgica de Enfermedades Respiratorias,

Hospitales Universitarios Virgen del

Rocío, Seville, Spain
Correspondence: José Luis Lopez-Campos Hospital Universitario Virgen del Rocío, Avda. Manuel Siurot, s/n, 41013 Seville, Spain

Tel +34955013 167

Fax +34955013167

Email lcampos@separ.es
Aim: It has been recently shown that the original BODE index has a high degree of correlation with two modified BODE indexes using maximal oxygen uptake expressed either as $\mathrm{mL} / \mathrm{min} / \mathrm{kg}$ $(\mathrm{mBODE})$ or as the percentage predicted $(\mathrm{mBODE} \%)$. In this study we investigated the agreement between the two modified BODE indexes ( $\mathrm{mBODE}$ and $\mathrm{mBODE} \%$ ) in patients with stable chronic obstructive pulmonary disease (COPD).

Methods: A total of 169 patients with stable COPD were enrolled in this cross-sectional study. Differences between the two mBODE indexes were assessed using kappa coefficients and Bland-Altman plots. One out of every three patients underwent the six-minute walking test to investigate the agreement with the original BODE index.

Results: Correlations between the two mBODE indexes with each other $(\mathrm{r}=0.96, P<0.001)$ and with the original BODE index (mBODE $\mathrm{r}=0.88, P<0.001 ; \mathrm{mBODE} \% \mathrm{r}=0.93$, $P<0.001)$ were excellent. However, the two $\mathrm{mBODE}$ indexes were significantly different from each other (mBODE $5.27 \pm 2.3$ versus mBODE\% $4.31 \pm 2.5 ; P<0.001$ ). The kappa coefficients were significantly lower (entire study group $\mathrm{k}=0.5, P<0.001$ ) for every GOLD stage. The mean difference between the two mBODE indexes was $0.8 \pm 0.6$ units. Differences with the original BODE were higher for the $\operatorname{mBODE}(1.8 \pm 0.9)$ than for the mBODE\% $\%$ (0.6 \pm 0.8$)$.

Conclusions: The new mBODE indexes are highly correlated but significantly different from each other. The differences between the novel indexes deserve further scrutiny.

Keywords: BODE index, chronic obstructive pulmonary disease, exercise testing, multidimensional evaluation, oxygen uptake

\section{Introduction}

Chronic obstructive pulmonary disease (COPD) is a progressive and debilitating lung disease characterized by irreversible airflow limitation in the lungs, which is predicted to have a trend of steadily increasing morbidity and mortality in the near future. ${ }^{1}$ In addition to causing inflammatory and structural changes in the lung resulting in alterations of ventilatory mechanics ${ }^{2}$ and gas exchange,${ }^{3}$ COPD may also have systemic manifestations, ${ }^{4}$ such as impairment in nutritional status ${ }^{5}$ and peripheral muscle dysfunction. ${ }^{6}$ In this context, a multidimensional grading system that assesses the respiratory and systemic expressions of COPD is important for categorization and outcome prediction.

Celli et $\mathrm{al}^{7}$ have recently introduced the use of the BODE index, a multidimensional 10 -point scale assessing four prognostic factors in COPD patients, namely body mass index (B), degree of airflow obstruction (O), functional dyspnea (D), and exercise capacity (E) as assessed by the six-minute walk test (6MWT). The BODE index has 
been extensively validated and shown to predict mortality ${ }^{7}$ and future hospitalizations. ${ }^{8}$ In addition, it has been found to be a good predictor of exacerbations ${ }^{9}$ and health-related quality of life. ${ }^{10}$

However, several modifications of the original BODE index have been proposed to obtain novel indexes that may be more accurate and easier to use. ${ }^{11,12}$ In this regard, the $6 \mathrm{MWT}$ used in the original BODE index is a submaximal test, is dependent on individual motivation, and may not express the real physical capacity of the patient. Interestingly, correlations with the maximal oxygen uptake $\left(\mathrm{VO}_{2 \max }\right)$ are only moderate. ${ }^{13}$ In contrast, maximal cardiopulmonary exercise testing (CPET) is considered the gold standard to assess maximal exercise tolerance. In particular, $\mathrm{VO}_{2 \max }$ is an objective measure of physical fitness and might serve as a physical training target, ${ }^{14}$ a predictor of survival rates, ${ }^{15}$ and a disability index for COPD patients. ${ }^{16}$ Of note, the original BODE index has been recently correlated with two modified BODE indexes replacing 6MWT with $\mathrm{VO}_{2 \max }$ expressed either as the percentage of predicted values ( $\mathrm{mBODE} \%$ ) or as absolute values in $\mathrm{mL} / \mathrm{min} / \mathrm{kg}$ (mBODE). ${ }^{17}$ Intriguingly, the modified BODE indexes have been recently linked to survival in COPD patients. ${ }^{18}$ In addition, a highly significant correlation between the original BODE and the modified indexes has been reported. ${ }^{17}$ It has been therefore suggested that the original BODE index is highly effective in the evaluation of COPD patients. Although valuable data have been presented - including the use of $\mathrm{VO}_{2 \max }$ in the BODE index - an analysis of the agreement between the two modified BODE indexes has not yet been performed. Therefore, the question as to whether these indexes may have the same properties remains open. The purpose of this study was to analyze the agreement between the two modified BODE indexes in a group of patients with stable COPD. We also sought to investigate the relation between the modified BODE indexes and the original BODE in a subsample of patients.

\section{Materials and methods}

This is an observational, cross-sectional, prospective study. All procedures were approved by the local Institution Review Board and written informed consent was obtained from all participants.

\section{Subjects}

A total of 169 COPD patients were included in the study. Study participants were recruited from our outpatient clinics during routine visits. Patients fulfilling the following inclusion criteria were invited to participate in the study: a) being an adult patient diagnosed as having COPD according to international guidelines ${ }^{19}$ and $b$ ) being clinically stable during the previous three months. Exclusion criteria were: a) recent exacerbations (in the previous three months) requiring systemic corticosteroids or antibiotics, ${ }^{20}$ and b) any contraindication or inability to perform any of the study tests (uncontrolled heart disease, acute pulmonary disease, and other conditions). ${ }^{14}$ Medications already prescribed were continued during the study.

Patients underwent a complete clinical and functional evaluation followed by a maximal CPET on a cycle ergometer. To be able to compare our findings with those achieved using the original BODE index, one out of every three patients performed the 6MWT according to international recommendations. ${ }^{21}$ Clinical and functional evaluation consisted of dyspnea scoring, nutritional evaluation, spirometric testing, and arterial blood-gas analysis.

\section{Measurements \\ Dyspnea}

Basal dyspnea was assessed using the modified Medical Research Council (MRC) scale. ${ }^{22}$ This is a five-point scale based on degrees of various physical activities that precipitate dyspnea.

\section{Nutritional status}

Nutritional status was assessed by calculating body mass index (BMI). BMI was obtained by dividing body weight in kilograms by height in square meters $\left(\mathrm{kg} / \mathrm{m}^{2}\right)$. A BMI of less than $21.0 \mathrm{~kg} / \mathrm{m}^{2}$ was considered to be underweight. ${ }^{7}$

\section{Pulmonary function tests}

Spirometric investigations were carried out on a pneumotachograph spirograph Masterlab (Erich Jaeger GMBH, Wuerzburg, Germany), following American Thoracic Society (ATS) recommendations. ${ }^{23}$ For the purpose of this study, values of forced expiratory volume in one second $\left(\mathrm{FEV}_{1}\right)$ were recorded. Blood-gas analyses were carried out with an ABL-700 analyser (Radiometer, Copenhagen, Denmark) using arterial blood samples taken from the radial or humeral artery at rest while the patient was breathing room air. Arterial oxygen partial pressure $\left(\mathrm{PaO}_{2}\right)$ carbon dioxide partial pressure $\left(\mathrm{PaCO}_{2}\right)$ and $\mathrm{pH}$ were recorded following the manufacturer's instructions and in keeping with Spanish Society of Pulmonology and Thoracic Surgery recommendations. ${ }^{24}$

\section{Maximal cardiopulmonary exercise test}

Maximal CPET was performed on a cycle ergometer (Collins Respiratory; ErgoMed, Seattle, WA, USA). Maximal exercise tolerance was measured by a symptom-limited graded 
exercise test performed while the patient was breathing room air. Breathing was continuously monitored, and inhaled and exhaled gases were collected. We determined the $\mathrm{VO}_{2 \text { peak }}$ and carbon dioxide production, an indirect measure of anaerobic threshold. $\mathrm{VO}_{2 \text { peak }}$ was expressed as an absolute value or as a percentage of the predicted value (in $\mathrm{mL} / \mathrm{min} / \mathrm{kg}$ ). An average of the last 20 seconds of each minute was used for the purpose of analysis. The respiratory pattern (maximal breathing capacity, tidal volume, respiratory rate) during exercise was carefully recorded. Electrocardiogram and pulse oxymetry monitoring were performed during exercise. Data for ventilation and gas analysis were instantly obtained and analyzed breath-by-breath by a computer connected with the cycle ergometer. Oxygen was measured by a zirconia cell and carbon dioxide by an infrared cell. Patients were monitored for three minutes at rest and then began to pedal without any resistance for one minute. The level of resistance was then increased by 10-15 watts every minute until the maximal exercise level was reached. After exercise, we assessed heart rate and blood pressure. Dyspnea, leg fatigue, and chest pain were assessed after exercise according to a modified Borg's scale. ${ }^{25}$

\section{Six-minute walking test}

The 6MWT was performed a few days before CPET following the current recommendations. ${ }^{21}$ Prior to the index test, a trial test was performed to avoid a training effect.

\section{Modified BODE Indexes}

The two mBODE indexes were calculated using BMI, FEV and MRC as in the original index. ${ }^{7}$ However, the use of $6 \mathrm{MWT}$ was replaced with $\mathrm{VO}_{2 \text { peak }}$ values, expressed either in $\mathrm{mL} / \mathrm{min} / \mathrm{kg}(\mathrm{mBODE})$ or as the percentage of predicted $(\mathrm{mBODE} \%)$. Each variable was rated on a four-point (0-3) scale, the only exception being BMI, which was coded as a dichotomous variable ( 0 or 1$)$. mBODE indexes were calculated as the sum score ranging from 1 to 10 . The scale was then divided into quartiles, with the first quartile corresponding to scores of 0-2 points, the second quartile to scores of 3-4 points, the third quartile to scores of 5-6 points, and the fourth quartile to scores of $7-10$ points. ${ }^{7}$ Although several different stratifications may be theoretically used, $\mathrm{VO}_{2 \text { peak }}$ values were stratified as proposed by Cardoso et al, ${ }^{17}$ to make results comparable. The values of $\mathrm{VO}_{2 \text { peak }}$ in $\mathrm{mL} / \mathrm{min} / \mathrm{kg}$ were therefore stratified according to previous methodology ${ }^{26}$ as follows: score $0 \geq 25 \mathrm{~mL} / \mathrm{min} / \mathrm{kg}$; score $1=20-25 \mathrm{~mL} / \mathrm{min} / \mathrm{kg}$; score $2=15-20 \mathrm{~mL} / \mathrm{min} / \mathrm{kg}$; score $3 \leq 15 \mathrm{~mL} / \mathrm{min} / \mathrm{kg}$. Similarly, values of $\mathrm{VO}_{2 \text { peak }}$ predicted were stratified ${ }^{27}$ as follows: score $0 \geq 70 \%_{\text {pred }}$; score $1=60 \%-69 \%_{\text {pred }}$; score $2=40 \%-59 \%_{\text {pred }}$; score $3 \leq 40 \%_{\text {pred }}$.

\section{Statistical analysis}

Statistical analysis was performed using the Statistical Package for Social Sciences (version 15.0; SPSS Inc., Chicago, IL, USA), Qualitative variables are expressed as absolute and relative frequencies. Quantitative variables are expressed as means and standard deviations. For descriptive purposes, variables are presented for the entire study cohort and according to GOLD stages. ${ }^{19}$ GOLD stages I and II were unified within one group since only eight patients had Stage I disease. Comparisons between qualitative variables were performed using the $\chi^{2}$ test or the Fisher's exact test.

Correlations were analyzed by calculating the Pearson's correlation coefficient (r). Comparisons of quantitative variables were performed using the Student's $t$ test. Differences across different GOLD stages were assessed using analysis of variance (ANOVA). Agreement between the mBODE and $\mathrm{mBODE} \%$ was studied using the kappa coefficient (k) according to the quartiles of the two mBODE indexes. The degree of agreement was also investigated using the Bland-Altman plot (difference versus average). In this method, the mean differences between measures are reported as means \pm 2 standard deviations in parentheses. ${ }^{28}$ The alpha error was set at 0.05 .

\section{Results \\ Comparison between modified BODE indexes}

The clinical and functional characteristics of the 169 participants are shown in Table 1. Correlations between the two $\mathrm{mBODE}$ indexes and the corresponding $\mathrm{VO}_{2 \text { peak }}$ value were good (mBODE index: $\mathrm{r}=-0.68, P<0.001 ; \mathrm{mBODE} \%$ index: $\mathrm{r}=-0.75, P<0.001)$. The correlation between the two mBODE indexes was excellent $(\mathrm{r}=0.96, P<0.001$, Figure 1). However, the two mBODE indexes were significantly different from each other (Table 1). These differences were evident for the entire cohort $(P<0.001)$ and throughout all GOLD stages $(P<0.001$ for all stages, Table 1$)$.

Kappa coefficients were significantly low in the entire study cohort $(\mathrm{k}=0.5, P<0.001)$, but improved in patients with advanced GOLD stages (GOLD I-II: $\mathrm{k}=0.49$, $P<0.001$; GOLD III: $\mathrm{k}=0.3, P<0.001$; GOLD IV: $\mathrm{k}=0.69, P<0.001)$.

Bland-Altman plots are presented in Figure 2. In the entire study cohort, the mean difference between the two mBODE indexes was $0.95(-0.46-2.37)$ units. The mean differences according to GOLD stages were as follows: GOLD I-II: 1.1 (-0.4-2.63); GOLD III: 1 (-0.35-2.35), and GOLD IV: $0.7(-0.5-1.98)$ units. 
Table I Clinical and functional characteristics of the 169 study participants

\begin{tabular}{|c|c|c|c|c|c|}
\hline Characteristics & Cohort $(n=169)$ & GOLD I-II $(n=63)$ & GOLD III $(n=53)$ & GOLD IV $(n=53)$ & $P$ value* \\
\hline Males & $165(97.6 \%)$ & $62(98.4 \%)$ & $50(94.3 \%)$ & $53(100 \%)$ & NS \\
\hline Age (years) & $64 \pm 7$ & $63 \pm 6$ & $64 \pm 7$ & $64 \pm 7$ & NS \\
\hline Dyspnea (MRC) & $2.12 \pm 1.2$ & $1.52 \pm 1.1$ & $2.3 \pm 0.9$ & $2.6 \pm 1.2$ & $<0.001$ \\
\hline BMI $\left(\mathrm{kg} / \mathrm{m}^{2}\right)$ & $28.6 \pm 5.09$ & $28.9 \pm 4.6$ & $28.9 \pm 4.6$ & $27.8 \pm 5.9$ & NS \\
\hline FVC (\%) & $81.6 \pm 17.9$ & $94.9 \pm 14.9$ & $77.1 \pm 13.2$ & $70.07 \pm 14.8$ & $<0.001$ \\
\hline $\mathrm{FEV}_{1}(\%)$ & $46.2 \pm 17.4$ & $64.1 \pm 12$ & $40.5 \pm 5.9$ & $30.5 \pm 10.3$ & $<0.001$ \\
\hline $\mathrm{FEV}_{1} / \mathrm{FVC}(\%)$ & $44.4 \pm 11.02$ & $53.6 \pm 7.8$ & $41.7 \pm 7.7$ & $35.7 \pm 8.5$ & $<0.001$ \\
\hline $\mathrm{pH}$ & $7.40 \pm 0.03$ & $7.4 I \pm 0.03$ & $7.39 \pm 0.02$ & $7.40 \pm 0.03$ & NS \\
\hline $\mathrm{PaCO}_{2}$ & $42.5 \pm 5.9$ & $39.6 \pm 3.6$ & $42.3 \pm 4.7$ & $45.8 \pm 7.4$ & $<0.001$ \\
\hline $\mathrm{PaO}_{2}$ & $70.5 \pm 10.4$ & $75.3 \pm 6.6$ & $74.1 \pm 7.9$ & $61.7 \pm 10.4$ & $<0.001$ \\
\hline CPET power (watts) & $63.7 \pm 32.4$ & $86.6 \pm 32.4$ & $59.4 \pm 23.1$ & $40.7 \pm 20.4$ & $<0.001$ \\
\hline $\mathrm{VO}_{2 \max }(\mathrm{mL} / \mathrm{min} / \mathrm{kg})$ & $16 \pm 4.9$ & $18.7 \pm 4.5$ & $15.2 \pm 4.3$ & $13.5 \pm 4.3$ & $<0.001$ \\
\hline $\mathrm{VO}_{2 \max }(\%)$ & $61.8 \pm 19.1$ & $72.9 \pm 18.1$ & $58.9 \pm 17.1$ & $51.4 \pm 15.1$ & $<0.001$ \\
\hline $\mathrm{mBODE}$ & $5.27 \pm 2.3$ & $3.1 \pm 1.6$ & $5.9 \pm 1.4$ & $7.5 \pm 1.7$ & $<0.001$ \\
\hline $\mathrm{mBODE} \%$ & $4.31 \pm 2.5$ & $2.02 \pm 1.8$ & $4.9 \pm 1.5$ & $6.4 \pm 1.9$ & $<0.001$ \\
\hline
\end{tabular}

*Calculated by ANOVA with the exception of gender analysis $\left(\chi^{2}\right.$ test). Data are expressed as means and standard deviations.

Abbreviations: NS, not significant; MRC, Medical Research Council scale; BMI, body mass index; FVC, forced vital capacity; FEV ${ }_{1}$, forced expiratory volume in one second; $\mathrm{PaCO}_{2}$, arterial carbon dioxide partial pressure; $\mathrm{PaO}_{2}$, arterial oxygen partial pressure; $\mathrm{CPET}$, cardiopulmonary exercise test; $\mathrm{VO}_{2 \text { max }}$, maximal oxygen uptake.

\section{Comparison of mBODE indexes with original $\mathrm{BODE}$}

In order to compare the mBODE indexes with the original BODE index, a subgroup of 54 patients (Table 2) performed the $6 \mathrm{MWT}$ (mean distance $517 \pm 118$ metres). There was a high correlation between original BODE and both the mBODE $(\mathrm{r}=0.88 ; P<0.001)$ and mBODE\% $(\mathrm{r}=0.93 ; P<0.001)$ indexes (Figure 3$)$. Kappa coefficients were low for both mBODE-BODE

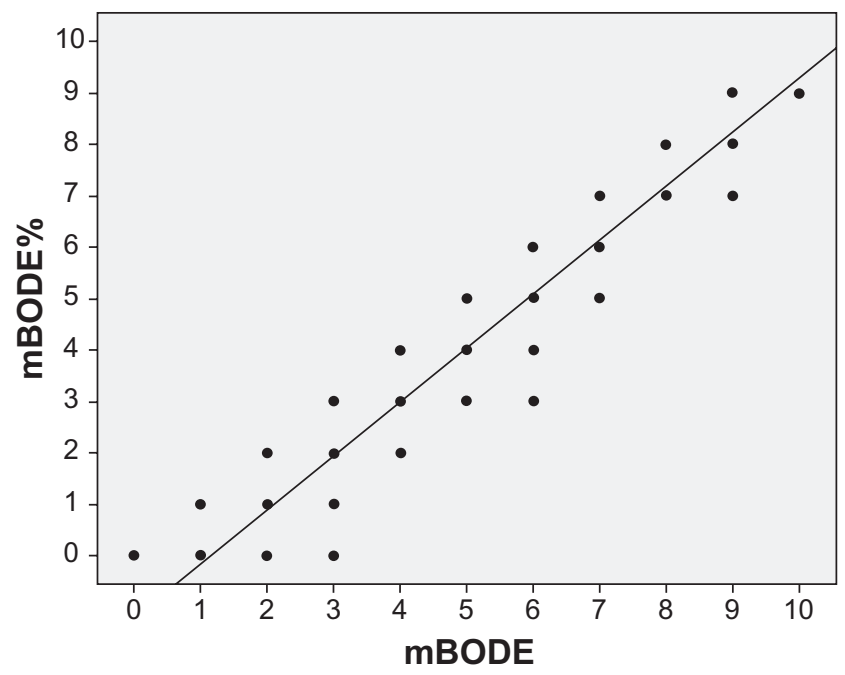

Figure I Scattergram and regression line showing a highly significant correlation between the two modified BODE indexes $(r=0.96, P<0.001)$. $(\mathrm{k}=0.12 ; P<0.001)$ and $\mathrm{mBODE} \%-B O D E(\mathrm{k}=$ $0.38 ; P<0.001)$. The agreement between the indexes was investigated using the Bland-Altman analysis. Results showed a mean difference in BODE points of $1.8(0.03-3.77)$ for $\mathrm{mBODE}$ and $0.6(-1.1-2.32)$ for $\mathrm{mBODE} \%$ (Figure 4).

\section{Discussion}

The present study demonstrates that the new modified BODE indexes are significantly different from each other with a mean difference of around 1 BODE point. These differences were less pronounced in the advanced stages of the disease, in which they were characterized by better agreement. Moreover, the agreement with the original BODE index was overall weak, and significantly lower for the mBODE than for the $\mathrm{mBODE} \%$.

The original BODE index is a simple multidimensional grading system which is superior to $\mathrm{FEV}_{1}$ alone for prediction of mortality and hospitalization rates among COPD patients. Since its first publication in $2004^{7}$ this index has been extensively used in different settings including pulmonary rehabilitation ${ }^{29}$ and lung volume reduction surgery. ${ }^{30}$ Several attempts have recently been made to improve the original BODE index, either by replacing or adding new components. ${ }^{11,12}$ In our study, two novel mBODE indexes were constructed by replacing $6 \mathrm{MWT}$ with $\mathrm{VO}_{2 \text { peak }}$ expressed either as the 

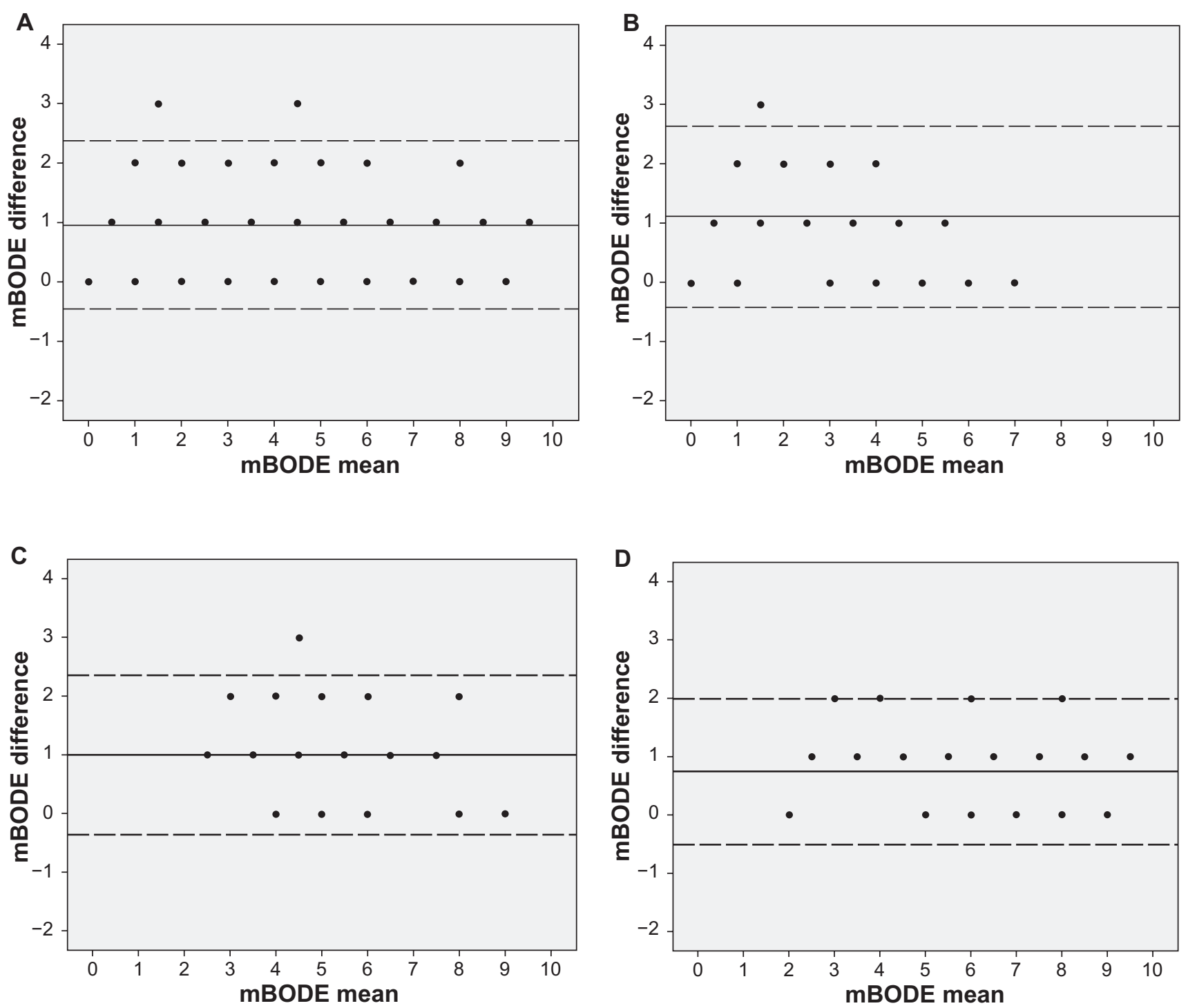

Figure 2 Bland-Altman plots exploring the differences between the two modified BODE indexes in A) the entire study cohort, as well as in B) patients with GOLD I-II, C) GOLD III, and D) GOLD IV. Mean differences: entire cohort: 0.95 (-0.46-2.37); GOLD I-II: I.I (-0.4I-2.63), GOLD III: I (-0.35-2.35), and GOLD IV: 0.7 (-0.5 -I.98) units.

percentage of predicted values (mBODE\%) or as the absolute values in $\mathrm{mL} / \mathrm{min} / \mathrm{kg}$ (mBODE). Although the novel indexes thus far have not been studied in detail, preliminary evidence has indicated that the $\mathrm{mBODE} \%$ and the original BODE index show similar prognostic properties. ${ }^{18}$

The identification of novel diagnostic tools is an important clinical goal. Novel diagnostic tools or multicomponent measures are frequently being developed to improve prognostic models and to identify novel therapeutic targets for patients with COPD. In this context, novel assessment tools need to be validated prospectively against pre-existing methodologies. Two previous studies have investigated and validated the novel mBODE indexes. ${ }^{17,18}$ To this end, a feasible approach is simple linear regression analysis, as previously done by
Cardoso et al. ${ }^{17}$ These authors have previously demonstrated a highly significant correlation between the original BODE index and the two mBODE indexes. Interestingly, in our study we were able to replicate these findings. However, it should be noted that the correlation between the original BODE index and $\mathrm{VO}_{2 \max }$ was only moderate. ${ }^{17}$ It is well known that good correlation does not necessarily imply good agreement and vice versa.$^{28}$ Therefore, the agreement between both indexes should be carefully evaluated by means of sound statistical analysis. The second report ${ }^{18}$ was a validation study of mBODE\% suggesting that this instrument has a good ability to predict mortality in a similar manner as the original BODE. However, the authors found a difference of 1.4 points between the $\mathrm{mBODE} \%$ and the original BODE. The study 
Table 2 Clinical and functional characteristics of participants performing the six-minute walking test

\begin{tabular}{|c|c|}
\hline Characteristic & Entire cohort $(n=54)$ \\
\hline Males & 51 (94.4\%) \\
\hline Age (years) & $63 \pm 7$ \\
\hline Dyspnea (MRC) & $1.09 \pm 0.7$ \\
\hline BMI $\left(\mathrm{kg} / \mathrm{m}^{2}\right)$ & $28.8 \pm 5.4$ \\
\hline FVC (\%) & $90.7 \pm 18.3$ \\
\hline $\mathrm{FEV}_{1}(\%)$ & $58.4 \pm 19$ \\
\hline FEV,/FVC (\%) & $49.9 \pm 10.8$ \\
\hline $\mathrm{pH}$ & $7.42 \pm 0.03$ \\
\hline $\mathrm{PaCO}_{2}$ & $40.6 \pm 5,5$ \\
\hline $\mathrm{PaO}_{2}$ & $71 \pm 9.7$ \\
\hline CPET power (watts) & $84.5 \pm 36$ \\
\hline $\mathrm{VO}_{2} \max (\mathrm{mL} / \mathrm{min} / \mathrm{kg})$ & $17.3 \pm 5.5$ \\
\hline $\mathrm{VO}_{2} \max (\%)$ & $71.4 \pm 20.9$ \\
\hline Six-minute walking test (metres) & $517 \pm 118$ \\
\hline
\end{tabular}

Data are expressed as means and standard deviations.

Abbreviations: MRC, Medical Research Council scale; BMI, body mass index; FVC, forced vital capacity; $\mathrm{FEV}$, forced expiratory volume in one second; $\mathrm{PaCO}_{2}$, arterial carbon dioxide partial pressure; $\mathrm{PaO}_{2}$, arterial oxygen partial pressure; $\mathrm{CPET}$, cardiopulmonary exercise test; $\mathrm{VO}_{2}$ max, maximal oxygen uptake.

did not focus on the degree of agreement between the two measures. The present report expands previous studies on the mBODE indexes by analyzing the degree of agreement between each other using the kappa and Bland-Altman plots. ${ }^{28}$ Future longitudinal studies are needed to investigate whether the two new mBODE indexes differ in their ability to predict mortality or exacerbations in patients with COPD. Although this issue has been partly addressed in the past, ${ }^{18}$

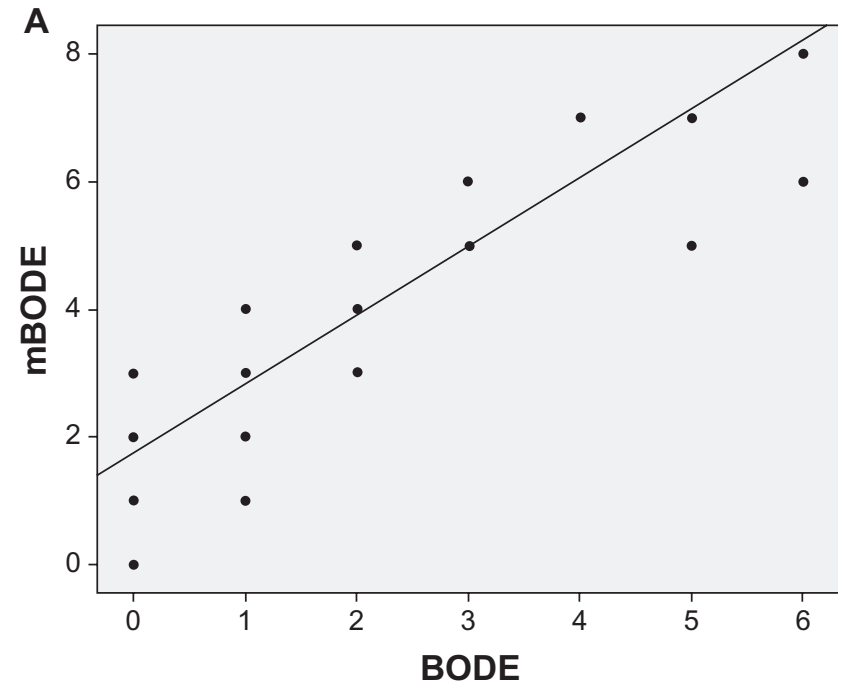

our study was not of prospective design and is therefore not suitable to confirm previous findings.

In our study, the two mBODE indexes showed a low degree of agreement, despite a high degree of correlation. Interestingly, kappa coefficients were low for the entire study cohort and in all GOLD stages, improving in advanced stages. Hence, a Bland-Altman plot of difference versus mean values showed a difference of about 1 point among the two mBODE indexes, which have proven to be a clinically relevant prognostic difference. ${ }^{31}$

Two findings of our study merit consideration. Firstly, patients in advanced stages of COPD had a higher degree of agreement. It is widely recognized that patients with advanced COPD suffer from severe impairment of functional capacity. ${ }^{32}$ In addition, the limitation in exercise capacity shows a lower variability in advanced stages characterized by a progressive reduction in the standard deviations of exercise variables (see Table 1). ${ }^{32}$ Secondly, the degree of agreement with the original BODE was different for the two $\mathrm{mBODE}$ indexes. Interestingly, the $\mathrm{VO}_{2 \text { peak }}$ is the only variable that differs between the two parameters. $\mathrm{VO}_{2 \text { peak }}$ is currently considered to be the best index of aerobic capacity and the gold standard for cardiorespiratory fitness. It represents the maximal achievable level of oxidative metabolism in large muscle groups. ${ }^{14} \mathrm{VO}_{2 \text { peak }}$ is generally expressed as oxygen uptake in absolute units. However, $\mathrm{VO}_{2 \text { peak }}$ can be normalized for body weight to compare $\mathrm{VO}_{\text {2peak }}$ among subjects with different anthropometric measures. ${ }^{33,34}$ Of note, $\mathrm{VO}_{2 \text { peak }}$ may be expressed in normalized and absolute units, ${ }^{35}$ and the two different modalities may express complementary facets

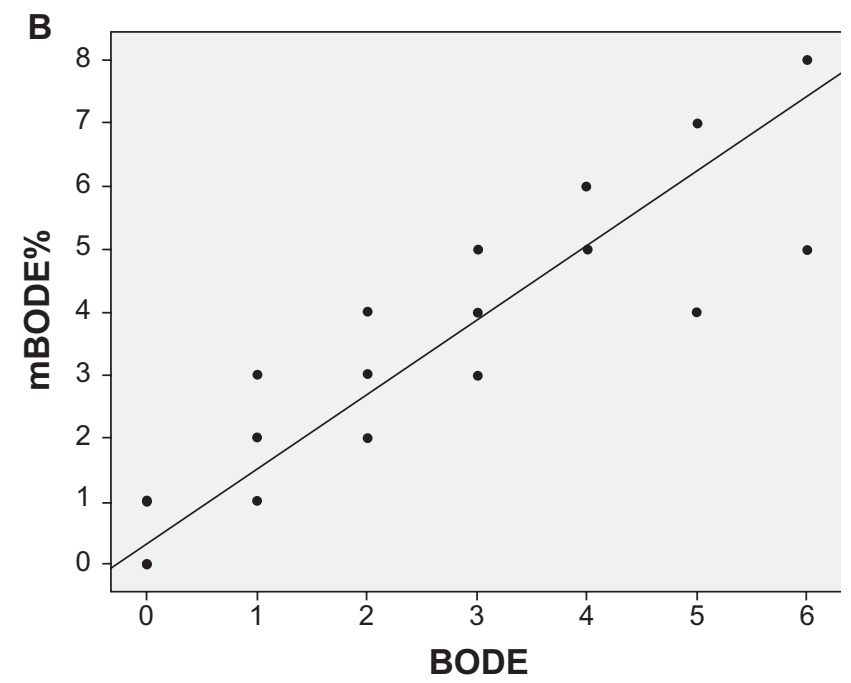

Figure 3 Scattergram and regression line showing a highly significant correlation between the original $B O D E$ and $\mathbf{A}) \mathrm{mBODE}(\mathrm{r}=0.88 ; P<0.00 \mathrm{I})$, as well as $\mathbf{B})$ the $\mathrm{mBODE} \%$ $(r=0.93 ; P<0.00 I)$. 

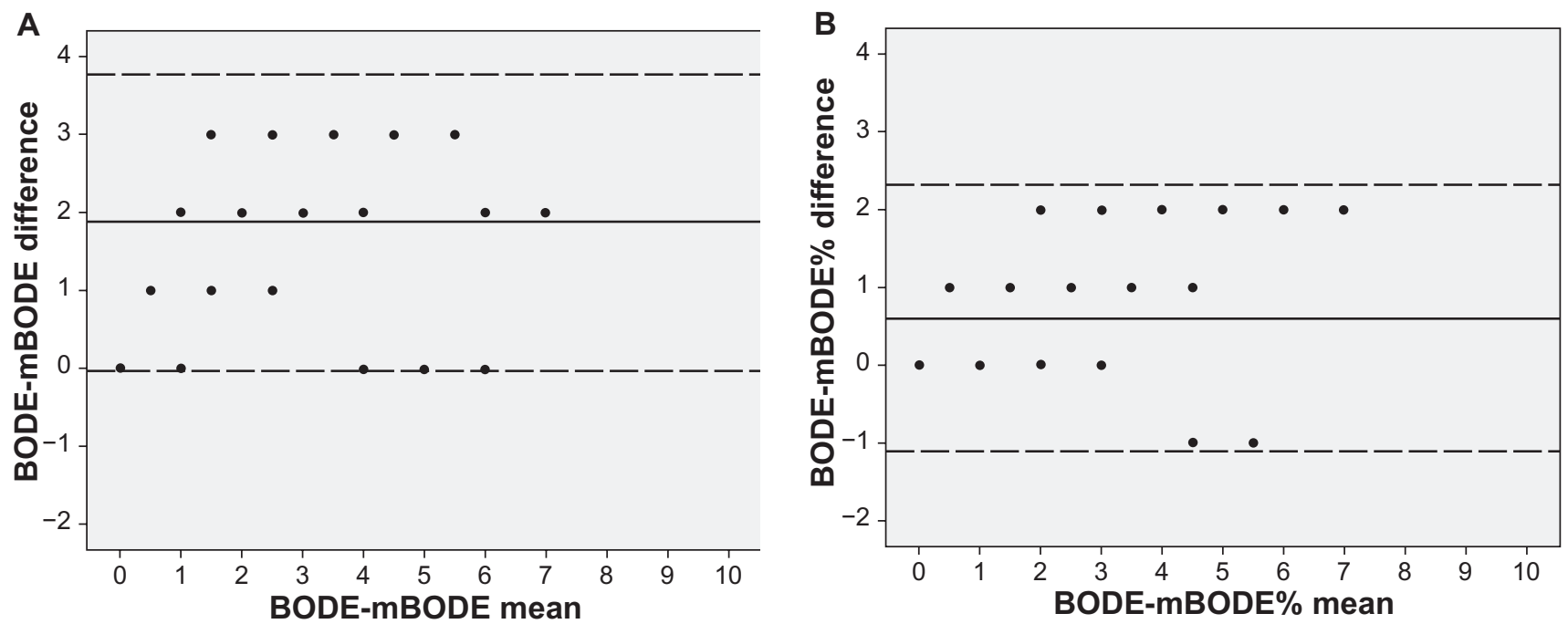

Figure 4 Bland-Altman plots exploring the differences between the original BODE and A) mBODE, mean difference I.8 (0.03-3.77), as well as $\mathbf{B})$ the $\mathrm{mBODE} \%$, mean difference $0.6(-1.1-2.32)$.

of aerobic capacity. It is possible that the use of different thresholds to stratify $\mathrm{VO}_{\text {2peak }}$ values could yield different results regarding correlation and agreement. This may also explain the differences in agreement observed between the original BODE and the $\mathrm{mBODE} \%$ compared with the mBODE. However, in this study we used the same thresholds proposed by Cardoso et $\mathrm{al}^{17}$ to ensure comparability. Future studies should investigate the optimal cut-off values for $\mathrm{VO}_{2 \text { peak }}$.

One difference between the present study and that of Cardoso et $\mathrm{al}^{17}$ relies in the use of a cycle ergometer for $\mathrm{VO}_{\text {2peak }}$ stratification instead of a treadmill. It is widely recognized that both methods have some differences. Maximal oxygen uptake is reported to be, on average, $5 \%-10 \%$ higher on a treadmill than on a cycle ergometer. Since some abnormalities may occur only at the highest metabolic demand, the exact determination of $\mathrm{VO}_{2 \max }$ in clinical practice is critical. ${ }^{14}$ It should be noted, however, that both methods have been validated for COPD patients, with no clear difference between the two forms of exercise. ${ }^{36}$

\section{Conclusions}

In summary, our study suggests that the novel mBODE indexes are highly correlated, but significantly different from each other (mean difference of approximately 1 BODE point) as well as from the original BODE index. Taken together, our data reinforce the idea that the original BODE index is useful in clinical characterization of COPD patients. Nonetheless, the differences between the two novel indexes deserve further scrutiny.

\section{Acknowledgements}

We are grateful to Enzo Emanuele for expert editorial assistance.

\section{Disclosures}

The authors report no conflict of interest in this work.

\section{References}

1. Mathers CD, Loncar D. Projections of global mortality and burden of disease from 2002 to 2030. PLoS Med. 2006;3:e442.

2. O'Donnell DE, Laveneziana P. The clinical importance of dynamic lung hyperinflation in COPD. COPD. 2006;3:219-232.

3. Bradley JM, Lasserson T, Elborn S, Macmahon J, O'Neill B. A systematic review of randomized controlled trials examining the short-term benefit of ambulatory oxygen in COPD. Chest. 2007;131:278-285.

4. Barnes PJ, Celli BR. Systemic manifestations and comorbidities of COPD. Eur Respir J. 2009;33:1165-1185.

5. Alcolea Batres S, Villamor Leon J, Alvarez-Sala R. Nutritional status in COPD. Arch Bronconeumol. 2007;43:283-288.

6. Couillard A, Prefaut C. From muscle disuse to myopathy in COPD: Potential contribution of oxidative stress. Eur Respir J. 2005;26:703-719.

7. Celli BR, Cote CG, Marin JM, et al. The body-mass index, airflow obstruction, dyspnea, and exercise capacity index in chronic obstructive pulmonary disease. $N$ Engl J Med. 2004;350:1005-1012.

8. Ong KC, Earnest A, Lu SJ. A multidimensional grading system (BODE index) as predictor of hospitalization for COPD. Chest. 2005;128:3810-3816.

9. Faganello MM, Tanni SE, Sanchez FF, Pelegrino NR, Lucheta PA, Godoy I. BODE index and GOLD staging as predictors of 1-year exacerbation risk in chronic obstructive pulmonary disease. Am J Med Sci. 2010;339:10-14.

10. Medinas Amorós M, Mas-Tous C, Renom-Sotorra F, Rubí-Ponseti M, Centeno-Flores MJ, Gorriz-Dolz MT. Health-related quality of life is associated with COPD severity: A comparison between the GOLD staging and the BODE index. Chron Respir Dis. 2009;6:75-80.

11. Soler-Cataluña JJ, Martínez-García MA, Sánchez LS, Tordera MP, Sánchez PR. Severe exacerbations and BODE index: Two independent risk factors for death in male COPD patients. Respir Med. 2009;103:692-699. 
12. Puhan MA, Garcia-Aymerich J, Frey M, et al. Expansion of the prognostic assessment of patients with chronic obstructive pulmonary disease: The updated BODE index and the ADO index. Lancet. 2009;374:704-711.

13. Casas A, Vilaro J, Rabinovich R, Mayer A, Barberà JA, et al. Encouraged 6-min walking test indicates maximum sustainable exercise in COPD patients. Chest. 2005;128:55-61.

14. American Thoracic Society, American College of Chest Physicians. ATS/ACCP statement on cardiopulmonary exercise testing. Am J Respir Crit Care Med. 2003;167:211-277.

15. Hiraga T, Maekura R, Okuda Y, et al. Prognostic predictors for survival in patients with COPD using cardiopulmonary exercise testing. Clin Physiol Funct Imaging. 2003;23:324-331.

16. Ortega F, Montemayor T, Sánchez A, Cabello F, Castillo J. Role of cardiopulmonary exercise testing and the criteria used to determine disability in patients with severe chronic obstructive pulmonary disease. Am J Respir Crit Care Med. 1994;150:747-751.

17. Cardoso F, Tufanin AT, Colucci M, Nascimento O, Jardim JR. Replacement of the 6-min walk test with maximal oxygen consumption in the BODE Index applied to patients with COPD: An equivalency study. Chest. 2007;132:477-482.

18. Cote CG, Pinto-Plata VM, Marin JM, et al. The modified BODE index: Validation with mortality in COPD. Eur Respir J. 2008;32: 1269-1274.

19. Global Initiative for Obstructive Lung Disease. 2008. Available from: http://www.goldcopd.com/. Accessed on February 18, 2010.

20. Rodriguez-Roisin R. Toward a consensus definition for COPD exacerbations. Chest. 2000;117(5 Suppl 2):398S-401S.

21. American Thoracic Society. ATS Statement: Guidelines for the SixMinute Walk Test. Am J Respir Crit Care Med. 2002;166:111-117.

22. Fletcher CM, Elmes PC, Fairbairn AS, Wood CH. The significance of respiratory symptoms and the diagnosis of chronic bronchitis in a working population. Br Med J. 1959;5147:257-266.

23. American Thoracic Society. Standardization of spirometry - 1987 update. Am Rev Respir Dis. 1987;136:1285-1298.

24. Recomendaciones SEPAR. Normativa Sobre Gasometría Arterial. 1st ed. Barcelona, Spain: Ediciones Doyma SA; 1987.
25. Borg G. Simple rating methods for estimation of perceived exertion. Wenner-Gren Center International Symposium Series. 1976;28:39-47.

26. American Medical Association. The Respiratory System. In: Guides to the evaluation of permanent impairment. 4th ed. Chicago, IL: American Medical Association; 1993.

27. Neder JA, Nery LE, Bagatin E, et al. Differences between remaining ability and loss of capacity in maximum aerobic impairment. Braz J Med Biol Res. 1998;31:639-646.

28. Bland JM, Altman DG. Statistical methods for assessing agreement between two methods of clinical measurement. Lancet. 1986;1: $307-310$.

29. Cote CG, Celli BR. Pulmonary rehabilitation and the BODE index in COPD. Eur Respir J. 2005;26:630-636.

30. Imfeld S, Bloch KE, Weder W, Russi EW. The BODE index after lung volume reduction surgery correlates with survival. Chest. 2006;129:873-878.

31. Martinez FJ, Han MK, Andrei AC, et al. Longitudinal change in the BODE index predicts mortality in severe emphysema. Am J Respir Crit Care Med. 2008;178:491-499.

32. Pinto-Plata VM, Celli-Cruz RA, Vassaux C, et al. Differences in cardiopulmonary exercise test results by American Thoracic Society/ European Respiratory Society - Global Initiative for Chronic Obstructive Lung Disease stage categories and gender. Chest. 2007;132: 1204-1211.

33. Ogawa T, Spina RJ, Martin WH 3rd, et al. Effects of aging, sex, and physical training on cardiovascular responses to exercise. Circulation. 1992;86:494-503

34. Jones NL, Summers E, Killian KJ. Influence of age and stature on exercise capacity during incremental cycle ergometry in men and women. Am Rev Respir Dis. 1989;140:1373-1380.

35. Puente-Maestu L. Reference values in adults. Eur Respir Mon. 2007; $12: 165-185$

36. Mathur RS, Revill SM, Vara DD, Walton R, Morgan MD. Comparison of peak oxygen consumption during cycle and treadmill exercise in severe chronic obstructive pulmonary disease. Thorax. 1995;50:829-833.
International Journal of COPD

\section{Publish your work in this journal}

The International Journal of COPD is an international, peer-reviewed journal of therapeutics and pharmacology focusing on concise rapid reporting of clinical studies and reviews in COPD. Special focus is given to the pathophysiological processes underlying the disease, intervention programs, patient focused education, and self management protocols.

\section{Dovepress}

This journal is indexed on PubMed Central, MedLine and CAS. The manuscript management system is completely online and includes a very quick and fair peer-review system, which is all easy to use. Visit http://www.dovepress.com/testimonials.php to read real quotes from published authors. 